\title{
Condiloma acuminado extenso en pene tratado exitosamente con Imiquimod crema al 5\%
}

\author{
Cortés JR, Arratia J, Martínez R, Gómez L. \\ Servicio de Urología. Hospital Universitario “Dr. José Eleuterio González” U.A.N.L. Monterrey. \\ Nuevo León. México.
}

Actas Urol Esp. 2007;31(3):276-278

\section{RESUMEN}

CONDILOMA ACUMINADO EXTENSO EN PENE TRATADO EXITOSAMENTE CON IMIQUIMOD CREMA AL 5\%

La infección por VPH está considerada como una de las causas más frecuentes de infecciones de transmisión sexual. Se han utilizado múltiples formas de tratamiento, que varían en su eficacia. Presentamos el caso de 2 pacientes con Condiloma Acuminado extenso en pene que fueron tratados exitosamente con Imiquimod crema al 5\%.

Palabras clave: Condiloma acuminado. Virus del papiloma humano. Imiquimod.

\section{ABSTRACT \\ EXTENSIVE CONDYLOMA ACUMINATA OF THE PENIS SUCCESSFULLY TREATED WITH 5\% IMIQUIMOD CREAM}

Infection by HPV is considered one of the most frequent causes of sexually transmitted infections. Multiple forms of treatment have been used that vary in their effectiveness. We describe 2 patients with Extensive Condyloma Acuminata in the penis successfully treated with treated with 5\% Imiquimod cream.

Keywords: Condyloma acuminata. Human papilloma virus. Imiquimod.

$\mathrm{L}^{\mathrm{a}}$ a infección por VPH está considerada como una de las causas más frecuentes de infecciones de transmisión sexual. Las verrugas genitales son la manifestación visible de la infección por los serotipos 6 y $11^{2,4}$. La prevalencia más alta, se encuentra entre los 20 y los 28 años de edad, tanto en varones y mujeres ${ }^{2,4}$. Además, el VPH tiene un rol importante en las lesiones preneoplásicas y neoplásicas del pene, como el cáncer espinocelular del pene, papulosis bowenoide, eritroplasia de Queyrat ${ }^{6}$.

A pesar de que este tipo de infecciones son muy comunes, se han utilizado múltiples formas de tratamiento, que varían en su eficacia y en el grado de molestia ocasionada al paciente. Se han descrito intentos de crioterapia, terapia con láser, aplicación tópica de podofilotoxina y de ácido tri- cloroacético. La mayoría de estas terapias, se enfocan principalmente en aliviar los sintomas eliminando la lesión, dejando de lado la prevención de la progresión a la malignidad. Otra opción de tratamiento es el Imiquimod al 5\% en crema (Aldara ${ }^{\circledR} 3 \mathrm{M}$ ), que en múltiples estudios ha resultado efectivo y bien tolerado ${ }^{1-5}$.

\section{CASOS CLÍNICOS Y MANEJO}

\section{Caso 1}

Varón de 27 años con antecedentes de promiscuidad sexual, tabaquismo y adicción a la cocaína. Acudió a nuestra consulta tras presentar lesión verrucosa en pene de 7 meses evolución, indolora, negando sintomatología urinaria. A la exploración física se observó lesión de tipo verrucoso en glande, de aproximadamente $3 \mathrm{~cm}$ 
de diámetro, friable (Fig. 1A). Se tomó biopsia de la lesión, reportándose como condiloma acuminado. Se le realizo prueba de detección del virus de inmunodeficiencia humana (VIH) por ELISA, la cual fue negativa. Se le indicó tratamiento mediante la aplicación de Imiquimod al 5\% en crema (Aldara $\left.{ }^{\circledR} 3 \mathrm{M}\right) 3$ veces por semana. Al completar una semana de tratamiento el paciente acudió a valoración, encontrándose la desaparición total de las lesiones (Fig. 1B).
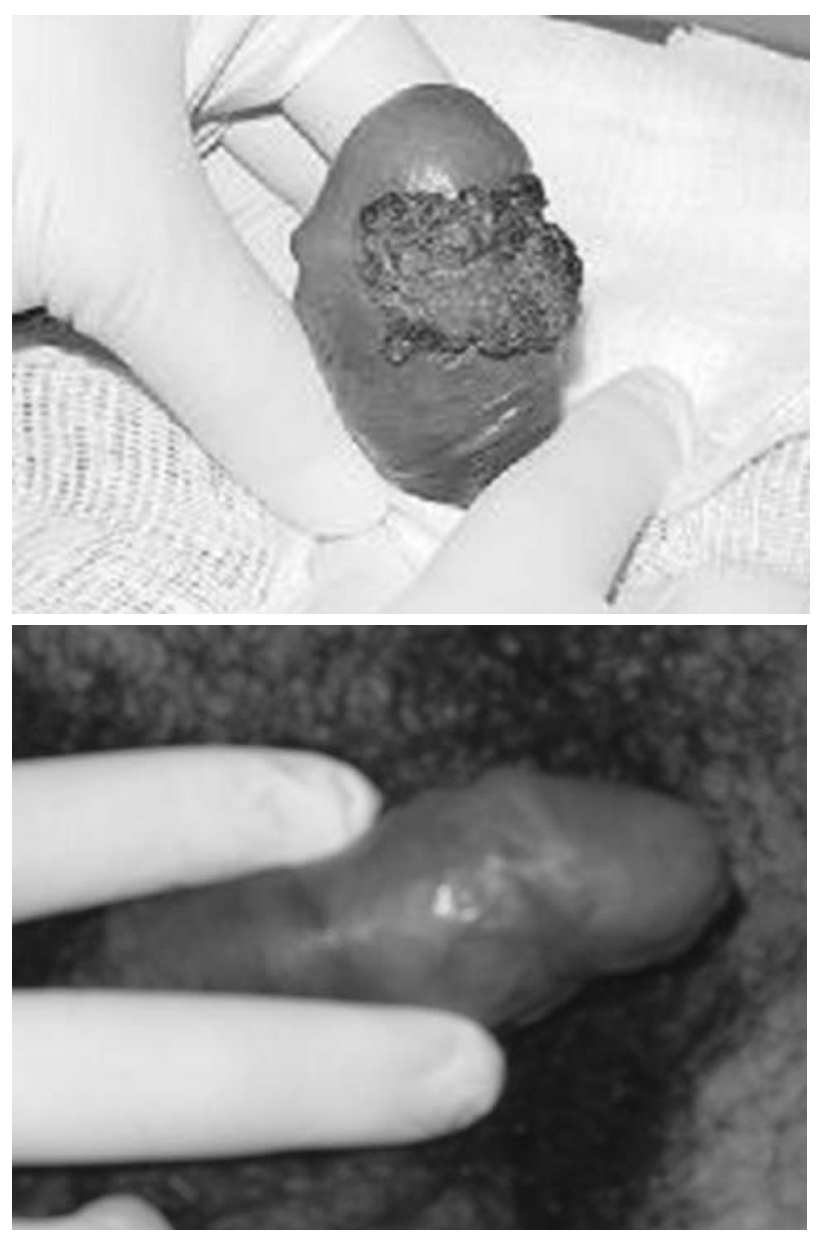

FIGURA 1. Condiloma acuminado previo al tratamiento (Imagen A), después de una semana de tratamiento (3 aplicaciones) (Imagen B).

\section{Caso 2}

Varón de 26 años con antecedentes de adicción a la marihuana, cocaína y promiscuidad sexual. Acudió a nuestro servicio tras presentar lesiones verrucosas en pene de un año de evolución, indoloras, las cuales progresivamente aumentaron en número y tamaño. Negaba síntomas urinarios. Al examen físico se aprecian múltiples lesiones verrucosas, friables, en glande y cuerpo del pene (Fig. 2A). Se le indicó tratamiento con imiquimod al 5\% en crema (Aldara ${ }^{\circledR} 3 \mathrm{M}$ ) tres veces por semana. El paciente acudió a consulta al completar dos semanas de tratamiento,
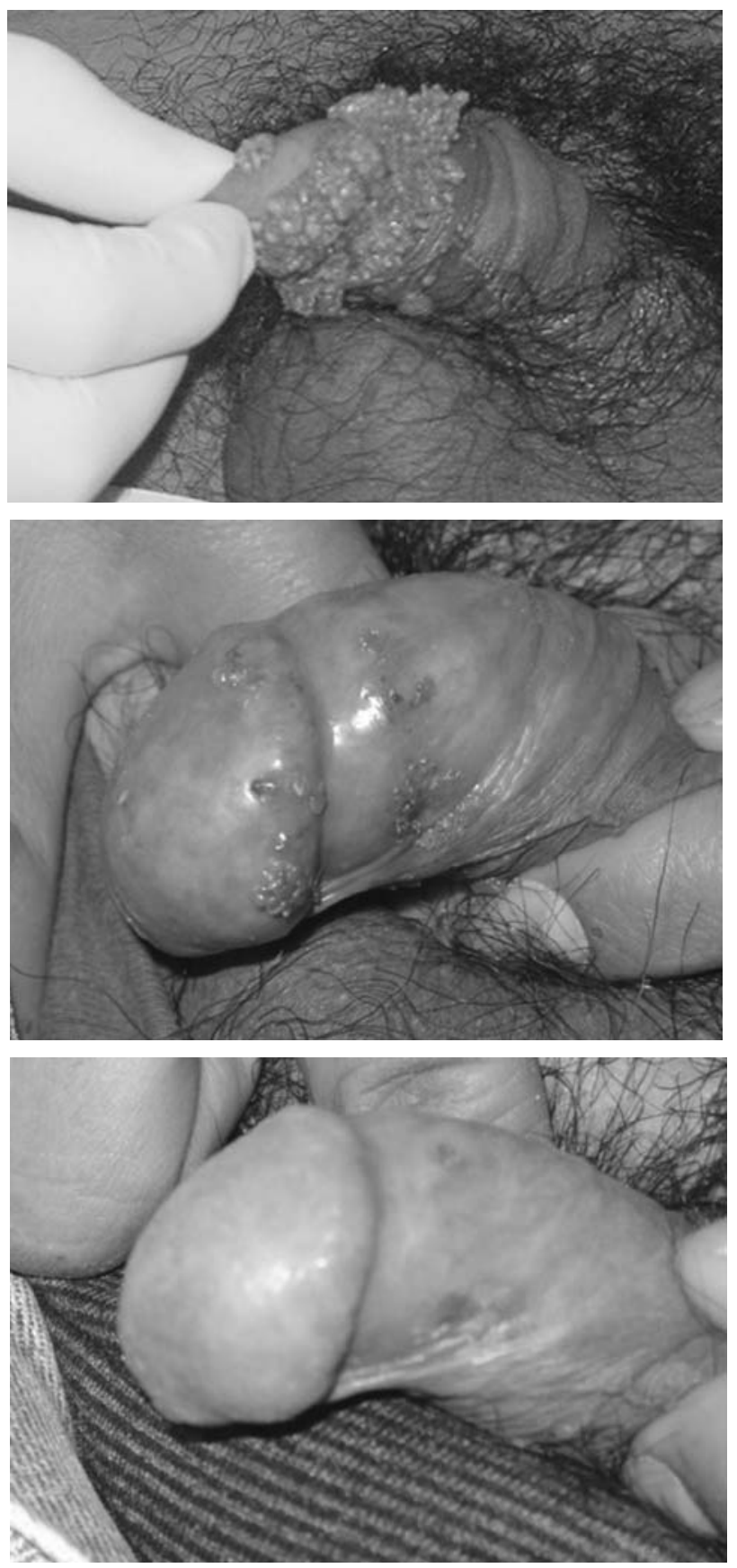

FIGURA 2. Condiloma acuminado previo al tratamiento (Imagen A), dos semanas después del tratamiento (Imagen B), 4 semanas después del tratamiento $\mathrm{C}$ ). 
encontrándose disminución importante en las lesiones tanto en su tamaño como en su número, apreciándose eritema importante en los sitios de las lesiones sin referir prurito o dolor en dichas zonas (Fig. 2B). Se continuó el tratamiento por 2 semanas más, al término de las cuales se revisó al paciente encontrándose la desaparición total de la lesiones.

\section{DISCUSIÓN}

Múltiples tratamientos se han utilizado para el tratamiento del condiloma acuminado. Algunos de ellos invasivos, que incluso requieren de anestesia local y además son de costo elevado ${ }^{1}$. El tratamiento con imiquimod al 5\% en crema ha sido eficaz en el tratamiento del condiloma acuminado, incluso en lesiones extensas como las que se presentaron en este trabajo ${ }^{2,3,5}$. Tiene la ventaja de ser un tratamiento tópico aplicado en casa, además de que la reacción inflamatoria ocasionada por la aplicación de la crema fue indolora y bien tolerada por los pacientes. Existen pocas aportaciones de casos similares con enfermedad extensa aportados en la literatura mundial. Se ha comprobado que el tratamiento con imiquimod crema al 5\% (Aldara® ${ }^{\circledR} \mathrm{M}$ ) tiene también efecto protector para disminuir las recidivas. Está descrito en algunos artículos, que la eficacia del tratamiento se observa hasta las 16 semanas, sin embargo, nosotros encontramos respuesta a las 4 semanas $^{1}$. El imiquimod al 5\% en crema (Aldara ${ }^{\circledR} 3 \mathrm{M}$ ) es un tratamiento eficaz, incluso en lesiones extensas, siendo además bien tolerado, de fácil aplicación y de costo accesible. Existen pocas publicaciones en pacientes con condiloma acuminado extenso en el pene. Las variaciones en el tiempo de tratamiento descritas en la literatura pueden estar relacionadas con los diferentes tipos de VPH por lo que futuras investigaciones clínicas deberán ser realizadas.

\section{REFERENCIAS}

1. Lafuma A, Monsonego J, Moyal-Barracco M, Pribil C. A model-based comparison of cost effectiveness of imiquimod versus podophyllotoxin for the treatment of external anogenital warts in France. Ann Dermatol Venereol. 2003; 130(89 Pt 1):731-736.

2. Cox JT. Extensive condyloma acuminata treated with imiquimod 5\% cream: a case report. Clin Exp Dermatol. 2003; 28(Suppl 1):51-54.

3. Weinberg JM, Stewart A, Stern JO. Successful treatment of extensive condyloma acuminata of the inguinal area and thigh with topical imiquimod cream. Acta Derm Venereol. 2001;81(1):76-77.

4. Moore RA, Edwards JE, Hopwood J, Hicks D. Imiquimod for the treatment of genital warts: a quantitative systematic review. BMC Infect Dis. 2001;1:3. Epub 2001.

5. Sauder DN, Skinner RB, Fox TL, Owens ML. Topical imiquimod $5 \%$ cream as an effective treatment for external genital and perianal warts in different patient populations. Sex Transm Dis. 2003;30(2):124-128.

6. Horenblas S, von Krogh G, Cubilla AL, Dillner J, Meijer CJ, Hedlund PO. Squamous cell carcinoma of the penis: premalignant lesions. Scand J Urol Nephrol Suppl. 2000;(205): 187-888.

Correspondencia autor: Dr. JR. Cortés González.

Servicio de Urología. Hospital Universitario "José E. González"

UANL. Avenida Madero y Gonzalitos s/n Col. Mitras Centro.

64460 Monterrey, NL. México

E-mail autor: jrcor77@yahoo.com

Información artículo: Nota clínica

Trabajo recibido: diciembre 2005

Trabajo aceptado: abril 2006 